\title{
Documentos
}

Discursos pronunciados en el Acto de Entrega de Medalla Rectoral a los académicos del Instituto de Estudios Internacionales de la Universidad de Chile, profesores María Teresa Infante y Alberto van Klaveren, el 27 de diciembre de 2018. 



\section{Discurso de presentación a cargo de la profesora Rose Cave}

Señor Rector de la Universidad de Chile, Doctor Ennio Vivaldi; señora Directora del Instituto de Estudios Internacionales, Doctora Dorotea López; señora Ministra ( $s$ ) de Relaciones Exteriores, Carolina Valdivia; autoridades y académicos de nuestra universidad; familiares y amigos de los homenajeados.

Asumo con humildad la honrosa responsabilidad de dirigirme a ustedes para referirme brevemente a la hoja de vida de dos académicos nuestros. Ellos son hoy objeto del más alto reconocimiento que otorga nuestra casa de estudios a los ex alumnos que se han destacado de manera especial por sus logros en pro de la universidad y del país. Es cierto que corresponde a la universidad entregar conocimientos a sus alumnos, formarlos en valores propios y universales, y proporcionarles los medios para que una vez egresados de sus aulas se abran paso en la vida y contribuyan al mayor bien del país. Sin embargo, subyace entre ambos una retroalimentación permanente, puesto que los alumnos aportan a la universidad sus capacidades y aptitudes, su voluntad, su esfuerzo y el entusiasmo en el ejercicio de la disciplina que eligieron, de manera que ambos resultan enriquecidos. Porque en definitiva, las instituciones son, en gran medida, lo que son las personas que forman parte de ellas.

Por esta razón, la Universidad de Chile ha instituido diversos galardones para distinguir a aquellos ex alumnos que a lo largo de su trayectoria profesional se han destacado entre sus pares por su desempeño y sus logros, enalteciéndoles a ellos y a su alma mater. El más importante de estos premios, reservado a los más preclaros, es la Medalla Rectoral, cuya entrega nos reúne hoy. El presente año, el señor Rector, con la anuencia de sus pares y tras un detenido estudio de los antecedentes del caso, ha resuelto entregarla a los académicos María Teresa Infante Caffi y Alberto van Klaveren Stork.

La trayectoria de ambos es, sin duda, de tan amplio conocimiento público que no necesitarían mayor presentación. Por ello, me limitaré a señalar solo algunos aspectos, en la esperanza de que contribuyan a dar aún más claridad a las razones por las cuales fueron elegidos para recibir esta alta distinción.

En lo que atañe a la profesora Infante, quizás como señal de las alturas que alcanzaría en el futuro, señalaría que ya desde sus primeros años da muestras de su inclinación por el estudio y de su vocación por la enseñanza. Ellas dieron su primer fruto manifiesto cuando ingresó a la carrera de Derecho con 
el puntaje más alto de su generación. Así, al titularse de abogado, en i974, era ya reconocida y como profesional tenía a sus pies las más altas posibilidades de distinguirse entre sus pares. El profesor Francisco Orrego Vicuña, recientemente fallecido, así lo entendió y la orientó hacia su perfeccionamiento en el extranjero. Transcurrió así un período en que realizó estudios de postgrado en la Universidad Complutense de Madrid, el Instituto de Altos Estudios Internacionales y de Desarrollo, en Ginebra, y la Academia de Derecho Internacional de La Haya. Como hija del rigor, tanto entonces como ahora, en todas las actividades en que ha participado, la profesora Infante no solo se ha distinguido por sus méritos intelectuales, sino también porque se ha entregado a ellas con un infatigable esfuerzo personal, imponiéndose una dura autodisciplina que no ha sabido de renuncias ni descansos. Como bien lo sabemos quienes hemos estado más cerca de ella, sin limitaciones de horario de trabajo.

Una vez de regreso en Chile, además de ejercer la docencia como profesora titular de Derecho Internacional Público en la Facultad de Derecho, entre 1987 y 1995 fue Directora del Instituto de Estudios Internacionales de nuestra universidad. La enseñanza ha llevado a la profesora Infante a importantes centros de estudio del país y del extranjero, en calidad de profesora visitante, lo que le ha permitido, a la vez, ampliar su propia perspectiva y absorber conocimientos y criterios nuevos. Sus nutridas publicaciones sobre el derecho internacional en general y temas especializados como el derecho del mar, la Antártica, y los asuntos limítrofes, la han dado a conocer en los más destacados círculos académicos.

Paralelamente a su carrera académica, la profesora Infante se incorporó a la administración pública y entre los años 1997 y 2014 se desempeñó como Directora de la División de Fronteras y Límites del Ministerio de Relaciones Exteriores de Chile. La DIFrol, como se conoce generalmente a la División, la condujo a otro hito importante de su carrera, cuando se le encomendó la responsabilidad de actuar como coagente, primero en la causa que enfrentó a Chile y Perú ante la Corte Internacional de Justicia y luego en la demanda interpuesta por Bolivia ante el mismo tribunal. En ambos casos, la profesora Infante desempeñó un papel fundamental no solo en el apoyo al equipo profesional chileno, el desarrollo de la estrategia jurídica aplicada y la cautela de los intereses de nuestro país, sino también como nexo invaluable en la relación con el medio social y académico.

Actualmente, la profesora Infante es Embajadora de Chile ante el Reino de los Países Bajos, donde le ha cabido una labor sobresaliente como diplomática y como profesional del derecho y donde, además de sus funciones ordinarias, ha participado con brillo en los trabajos de la Corte Penal Internacional y de la Organización para la Prohibición de las Armas Químicas. En todas estas actividades ha dejado su impronta como mujer y como profesional de excelencia. 
Sin duda, ellas han contribuido al gran prestigio de que disfruta en los círculos académicos y diplomáticos del país y, de paso, han aportado al respeto que se tiene en el extranjero por los profesionales chilenos. Sin embargo, no contenta con todo esto y dando muestra de su profundo sentido humano, ha sumado a estas actividades su notable labor como núcleo aglutinador de los numerosos chilenos que realizan estudios de postgrado en los Países Bajos, brindándoles familiar acogida y destinándoles parte generosa de su limitado tiempo.

Todo lo anterior, que es una síntesis muy breve de su trayectoria, justificaría con creces que se le otorgue la Medalla Rectoral. Sin embargo, para configurar un perfil cabal de sus méritos, cometería un grave error si, a riesgo de herir su particular modestia, no mencionara que a sus conocimientos y experiencia profesionales, es indispensable sumar su extraordinaria capacidad de acercarse a las personas, su profunda sencillez, su alegría en el servicio y su generosa y permanente disposición a compartir sus conocimientos y experiencia con todo aquel que le pida ayuda.

Me une a la profesora Infante una invaluable amistad de varias décadas y ello ha permitido que cada día aumente mi admiración por sus condiciones humanas y profesionales, así como mi fe en lo que se vislumbra para su futuro, que siempre ha de centrarse en el bien de Chile. Porque en un mundo cada vez más frío e indiferente, su sentido cívico, su total prescindencia de intereses políticos personales cuando se trata de trabajar por el país y por la universidad, de seguro han contribuido a que sea distinguida con el galardón que hoy recibe. Todo reafirma sus grandes méritos y, conociendo su grado de compromiso, será un motivo más para que siga entregándose a la comunidad y al país aún con mayor empeño.

Por su parte, el profesor van Klaveren, también merecedor del premio Medalla Rectoral el presente año, es un preclaro representante de las generaciones de profesionales egresados de nuestra universidad. Tras una niñez de adaptación a un nuevo país y un nuevo idioma, la dura historia de su familia y sus propias preferencias, tal vez estimuladas por el afán de responder al país que le había dado acogida, lo inclinaron hacia el derecho. Así, en 1972 obtuvo en nuestra universidad su Licenciatura en Ciencias Jurídicas y Sociales con distinción máxima.

Inspirado en las enseñanzas del profesor Gustavo Lagos Matus, que concebía un sistema internacional menos desigual, que pudiera evolucionar hacia un grado más alto de cooperación, el profesor van Klaveren fue orientando sus intereses hacia la especialización en relaciones internacionales. En una época difícil para el desarrollo de las ciencias sociales, se centró en el estudio de temas como las relaciones internacionales de América Latina y las relaciones chilenas y latinoamericanas con Europa occidental, incluyendo los proyectos de integración. Con el tiempo, sus investigaciones lo condujeron a profundizar 
temas más politológicos que jurídicos y perseverar en una preocupación por la formulación racional e inteligente de la política exterior de nuestro país. Contribuyeron a ello sus estudios de postgrado, primero su título de Magíster en Estudios Internacionales de la Universidad de Denver, Estados Unidos, y luego su Doctorado en Ciencia Política de la Universidad de Leiden, Países Bajos, que en definitiva marcaron su destino profesional.

Como bien lo expresó el profesor Manfred Wilhelmy en el discurso que pronunció en 20I5, en la entrega a su colega del Doctorado Honoris Causa de la Universidad Católica de Valparaíso, parte importante de las inquietudes intelectuales del profesor van Klaveren encontraron expresión en encuentros académicos y publicaciones que contribuyeron al avance de los estudios internacionales.

Entre 1985 y 1992, mientras estuvo radicado en España, cumplió importantes labores docentes en el Instituto de Relaciones Europeo-Latinoamericanas; la Asociación de Investigación y Especialización sobre Temas Iberoamericanos (AIETI); el Instituto Universitario Ortega y Gasset, y el Instituto de Ciencia Política de la Universidad de Heidelberg, en Alemania. También fue Asesor Principal de un proyecto de asesoramiento en política exterior del Programa de las Naciones Unidas para el Desarrollo (PNUD). Fue, sin duda, un período rico en experiencias que dio cuenta de su aporte en el avance de la cooperación académica interregional.

Entre sus numerosas actividades profesionales habría que agregar, al menos, su participación en el Programa de Estudios Conjuntos sobre las Relaciones Internacionales de América Latina (RIAL); el Proyecto de Apoyo al Ministerio de Relaciones Exteriores de Chile, y el Proyecto de Seguimiento de Políticas Exteriores Latinoamericanas (PROSPEL). El hecho de que entre 1995 y 1996 fuera Director del Instituto de Estudios Internacionales revela que nunca ha dejado de lado su labor por nuestra universidad.

Gracias al prestigio que le han dado su experiencia profesional y sus condiciones personales, entre las cuales se destacan su serenidad para enfrentar situaciones de crisis, su agudo criterio analítico y su dedicación al trabajo, fue llamado a Chile para asumir responsabilidades en el gobierno, primero como Embajador ante la Unión Europea, Bélgica y Luxemburgo, y entre 2006 y 2009 , como Subsecretario de Relaciones Exteriores. El hecho de haber sido elegido para desempeñarse como Agente del Estado de Chile ante la Corte Internacional de Justicia en el caso "Perú contra Chile: delimitación marítima" revela que se ha sabido apreciar no solo su capacidad de asumir las tareas más delicadas en la defensa de Chile, sino también su disposición a entregar lo mejor de sí para velar por los más altos intereses de un país en el cual no nació, pero que lo adoptó como hijo suyo. 
Las diversas funciones que ha cumplido a lo largo de su vida profesional dan fe de su profundo compromiso con nuestros principales valores. Sin abandonar su serenidad, su equilibrio en las situaciones más difíciles, ha dado muestras de que aún cuando los tiempos son más inciertos, es posible conservar el optimismo y el buen humor.

El profesor van Klaveren ha dejado su impronta en todas sus actuaciones y hasta el I de octubre del presente año, fecha en que se conoció el fallo de la Corte Internacional de Justicia en el caso en que Bolivia nos llevó por segunda vez en poco tiempo a enfrentar la justicia internacional, demostró poder conservar la calma y la ecuanimidad, esenciales para sortear los escollos que salen al paso en el día a día de un país orgulloso de su tradición jurídica y respetuoso del imperio del derecho.

Para terminar, querría destacar cuan feliz ha sido la coincidencia de poder distinguir en un mismo acto a dos académicos formados en la misma disciplina pero que, cada cual por su propio camino, han entregado lo mejor de sí por el bien de Chile. Unidos en torno a un ideal común, confiamos que en el futuro otros se sumarán a los profesores Infante y van Klaveren para conducir a nuestro país por la senda de la paz, la justicia y la verdad, que todos anhelamos. 
